\title{
Effect of Metformin Only versus Effect of Metformin and Corticosteroids after Laparoscopic Ovarian Drilling on Ovulation in Women with Clomiphene Citrate Resistant Polycystic Ovary Syndrome
}

\author{
Ismail Talaat El-Garhi, Fahd Abdel Aal El-Omda, Gamal Zakaria El-Khatib, Ahmed \\ Mohamed Fathy Awad \\ *Department of Obstetrics and Gynecology, Faculty of Medicine, Al-Azhar University \\ Corresponding author: Ahmed Mohamed Fathy Awad, Mobile: 02001222676432
}

\begin{abstract}
Background: the syndrome of polycystic ovary syndrome (PCOS) is clinically and biochemically heterogeneous. Medical treatment of PCOS is tailored to the patient's goals. Broadly, these may be considered fewer than four categories: lowering of insulin levels, restoration of fertility, treatment of hirsutism acne and restoration of regular menstruation. Objective: this study aimed to study the effect of Metformin alone after laparoscopic ovarian drilling on ovulation in women with clomiphene citrate resistant polycystic ovary syndrome in comparison with studying the effect of Metformin with Dexamethasone after laparoscopic ovarian drilling on ovulation in women with clomiphene citrate resistant polycystic ovary syndrome. Methodology: in the present study, 60 patients with PCO were resistant to clomiphene citrate therapy had undergone ovarian drilling. Those patients had been classified into 2 groups according to the selected therapy. Two trails had been compared; group A received metformin ( $850 \mathrm{mg}$ twice daily) plus dexamethasone ( $2 \mathrm{mg}$ daily from day 5 to day 14 monthly) for 3 months while group B had received metformin only ( $850 \mathrm{mg}$ twice daily).Results: our study showed no significant correlation between serum progesterone level after therapy and different parameters in both study groups. Conclusion: we concluded that there was a good value of administration of Dexamethasone with Metformin after laparoscopic ovarian drilling in patients with clomiphene resistant polycystic ovarian disease especially those patients with normal DHEAS levels.
\end{abstract}

Keywords: metformin, corticosteroids, PCOS.

\section{Introduction}

Polycystic ovary syndrome (PCOS) is the most common cause of infertility in women, frequently becomes manifest during adolescence and it is primarily characterized by ovulatory dysfunction and hyper-androgenism. The syndrome is hetero-geneous clinically and biochemically ${ }^{(\mathbf{1})}$.The diagnosis of PCOS has lifelong implications with increased risk for metabolic syndrome, type 2 diabetes mellitus and possibly cardiovascular disease and endometrial carcinoma. PCOS should be considered in any adolescent girl with a chief complaint of hirsutism, treatment-resistant acne, menstrual irregularity, or obesity (2). Functional ovarian hyperandrogenism was usually the major source of the androgen excess and can account for the major features of the syndrome, ie, hirsutism, anovulation and polycystic ovaries. This ovarian dysfunction was unique: it appeared to be intrinsic and was characterized by abnormal ovarian steroidogenesis and folliculogenesis that were manifested clinically by androgen excess and anovulation ${ }^{(3)}$.
Hyperandrogenism is a central feature for most forms (phenotypes) of PCOS. The androgens are secreted primarily by the ovaries and secondarily by the adrenals. Although hyperinsulinism is associated with hyperandrogenism in PCOS, insulin resistance alone is not sufficient for the development of PCOS, suggesting that an underlying (genetic) predisposition to hyperandrogenism must also be present ${ }^{(4)}$.Women with polycystic ovary syndrome (PCOS) have multiple abnormalities that require attention, including oligomenorrhea, hyperandrogenism, anovulatory infertility, and metabolic risk factors such as obesity, insulin resistance, dyslipidemia, and impaired glucose tolerance. Weight loss, which can restore ovulatory cycles and improve metabolic risk, is the first-line intervention for most women. our overall approach is similar to that described by the 2013 Endocrine Society Clinical Guidelines ${ }^{(5)}$.

Legro et al. stated that clomiphene citrate was the first-line therapy for ovulation induction in non-obese women with PCOS (BMI $<30 \mathrm{~kg} / \mathrm{m}^{2}$ ); approximately 80 percent of women 
with PCOS ovulate in response to clomiphene citrate and approximately 50 percent conceive ${ }^{(5)}$. Metformin was a potential alternative to restore menstrual cyclicity as it restores ovulatory menses in approximately 30 to 50 percent of women with PCOS. Its ability to provide endometrial protection is less well established, and we therefore consider it to be second-line therapy when metformin is used. Tang et al. suggested monitoring to confirm that ovulatory cycles have been established. This can be done with luteal phase serum progesterone measurements or transvaginal ultrasound ${ }^{(\boldsymbol{}}$. Corticosteroids reduced adrenal androgen production by negative feedback inhibition of adrenocorticotrophic hormone production. So the administration of low doses of corticosteroids may be of benefit to women with hyperandrogenic anovulation ${ }^{(7)}$.

Aim of the Work

The aim of the current study was to compare the effect of Metformin administration after laparoscopic ovarian drilling with the effect of adding Dexamethasone to Metformin after laparoscopic ovarian drilling on ovulation in Clomiphene Citrate resistant women with polycystic ovary syndrome.

Patients and Methods

\section{Study Design:}

clinical trial.

Comparative controlled randomized

\section{Study Setting:}

All patients were recruited from Infertility Clinic of Port Said General Hospital. Time of study:

Study was done in the period from July 2017 to May 2018. The study was approved by the Ethics Board of Al-Azhar University.

\section{Study Population: \\ Inclusion criteria:}

Clomiphene resistant women with a diagnosis of PCOs (according to Rotterdam's criteria) which depend on the presence of at least 2 of the following:

- Oligomenorrhea or amenorrhea.

- Clinical or laboratory evidence of hyperandrogenism.

- Polycystic ovaries by ultrasound.

\section{Exclusion criteria:}

1. Any medical or surgical contraindication for laparoscopy.

2. Certain diseases related to the adrenal gland as congenital adrenal hyperplasia, Cushing syndrome, etc.
3. Contraindications to Metformin administration as severe renal or liver disease.

4. Contraindications to Dexamethasone as systemic fungal infection or documented hypersensitivity.

\section{Methodology:}

In our study, 60 women with CC-resistant PCOS were recruited in the current trial. All included women were subjected to the following:

- History taking with particular emphasis on past medical history, menstrual history and infertility workup.

- General, abdominal and local examination.

- Bilateral laparoscopic ovarian drilling through creation of $8-15$ holes, each one 2 $-4 \mathrm{~mm}$ deep on the surface and stroma of each ovary using a unipolar electrode at 30 $40 \mathrm{~W}$ for $2-4$ seconds, was carried out postmenstrual in laparoscopy unit at port said general hospital.

- After drilling patients were divided in to 2 groups:

- Group I included 30 patients who were received oral Metformin 850 $\mathrm{mg}\left(\right.$ Cidophage $\left.^{\circledR}\right)$ twice daily for 3 months.

- Group II received oral Dexamethasone $2 \mathrm{mg}$ daily from day 5to day 14 and oral Metformin850mg twice daily for 3 months.

- Mid luteal serum progesterone was measured in the next 3 cycles for the 2 groups as an indicator of ovulation where normal mid luteal serum level are between 6 and $25 \mathrm{ng} \backslash \mathrm{ml}{ }^{(8)}$.

- Elimination of bias:

- Patients were randomly distributed in the 2 study groups.

- Mid luteal serum progesterone was measured in the same lab.

Successful ovulation as documented by Midluteal serum progesterone between 6 and 25 $\mathrm{ng} \backslash \mathrm{ml}$ in the next 3 cycles ${ }^{(8)}$, it was confirmed by TVS for assessment of the ovarian volume which was reduced from $15 \mathrm{~mm} 3$ to $10 \mathrm{~mm}^{3}$.

\section{Secondary Outcome:}

- Laparoscopic related complications.

- Menstrual regularity.

- Conception rate.

\section{Statistical analysis:}


Data were fed to the computer and analyzed using IBM SPSS (Statistical Package for the Social Science) software package version 20 as follows: qualitative data were described using number and percent, quantitative data were described using range (minimum and maximum), mean \pm standard deviation (SD) and median. Comparison between different groups regarding categorical variables was tested using Chi-square test. $\square$ For abnormally distributed data, comparison between 2 independent populations were done using Mann Whitney test while Kruskal Wallis test was used to compare between different groups. Significance test results are quoted as 2-tailed probabilities. Significance of the obtained results was judged at the 5\% level.
All results were considered insignificant if Pvalue $>0.05$, significant: if $P$ - value $\leq 0.05$, and highly significant: if $\mathrm{P}$-value $\leq 0.001$.

\section{Results}

In the present study, 60 patients with PCO were resistant to clomophine citrate therapy had undergone ovarian drilling. Those patients had been classified into 2 groups according to the selected therapy. Two trails had been compared; group A had received metformin $(850 \mathrm{mg}$ twice daily) plus dexamethasone ( $2 \mathrm{mg}$ daily from day 5 to day 14 monthly) for 3 months, while group B had received metformin only $(850 \mathrm{mg}$ twice daily).

Table 1: Baseline clinical data of both study groups

\begin{tabular}{|c|c|c|c|c|}
\hline & & \begin{tabular}{|l} 
Group A \\
$\mathbf{N}=\mathbf{3 0}$
\end{tabular} & \begin{tabular}{|l|} 
Group B \\
$\mathbf{N}=\mathbf{3 0}$ \\
\end{tabular} & p-value \\
\hline \multirow[t]{2}{*}{ Age (years) } & Mean \pm SD & $29.86 \pm 3.99$ & $30.87 \pm 3.23$ & \multirow{2}{*}{$\begin{array}{l}0.190^{\mathrm{a}} \\
(\mathrm{NS})\end{array}$} \\
\hline & \begin{tabular}{|l|} 
Range \\
\end{tabular} & $23-36$ & $26-37$ & \\
\hline \multirow[t]{2}{*}{ BMI $\left(\mathrm{Kg} / \mathbf{m}^{2}\right)$} & Mean \pm SD & $27.68 \pm 1.72$ & $27.78 \pm 1.57$ & \multirow{2}{*}{$\begin{array}{l}0.840^{\mathrm{a}} \\
(\mathrm{NS})\end{array}$} \\
\hline & Range & $25-30$ & $25-30$ & \\
\hline \multirow[t]{2}{*}{ Type of infertility } & \begin{tabular}{|l|} 
Primary \\
\end{tabular} & $20(66.7 \%)$ & $18(60 \%)$ & \multirow{2}{*}{$\begin{array}{l}0.789 \chi^{2} \\
\text { (NS) }\end{array}$} \\
\hline & Secondary & $10(33.3 \%)$ & $12(40 \%)$ & \\
\hline \multirow{2}{*}{$\begin{array}{l}\text { Duration of infertility } \\
\text { (months) }\end{array}$} & Mean \pm SD & $28.56 \pm 7.55$ & $29.63 \pm 7.08$ & \multirow{2}{*}{$\begin{array}{l}0.667^{\mathrm{a}} \\
(\mathrm{NS})\end{array}$} \\
\hline & Range & $18-41$ & $17-41$ & \\
\hline \multirow[t]{2}{*}{ Menstrual pattern } & \begin{tabular}{|l|} 
Regular \\
\end{tabular} & $8(26.7 \%)$ & $10(33.3 \%)$ & \multirow{2}{*}{$\begin{array}{l}0.779 \chi^{2} \\
\text { (NS) }\end{array}$} \\
\hline & \begin{tabular}{|l} 
Oligomenorrhea \\
\end{tabular} & $22(73.3 \%)$ & $20(66.7 \%)$ & \\
\hline
\end{tabular}

(NS): no statistically significant difference, ${ }^{\text {a: }}$ Mann Whitney test, $\chi^{2}$ : Chi square test

This table showed that both groups were matched for age, BMI, duration and type of infertility and menstrual pattern.

Table 2: Comparison between both groups as regards baseline hormonal profiles

\begin{tabular}{|c|c|c|c|c|}
\hline & & $\begin{array}{l}\text { Group A } \\
\mathbf{N}=\mathbf{3 0}\end{array}$ & $\begin{array}{l}\text { Group B } \\
\mathbf{N}=\mathbf{3 0}\end{array}$ & p-value \\
\hline \multirow[t]{2}{*}{ Ovarian volume (mm) } & Mean \pm SD & $10.50 \pm 2.1$ & $10.38 \pm 1.91$ & \multirow{2}{*}{$\begin{array}{l}0.976^{a} \\
(\mathrm{NS})\end{array}$} \\
\hline & Range & $8-14$ & $8-14.5$ & \\
\hline \multirow[t]{2}{*}{ Progesterone pg/ml } & Mean \pm SD & $1.94 \pm 0.30$ & $1.89 \pm 0.13$ & \multirow{2}{*}{$\begin{array}{l}0.736^{a} \\
\text { (NS) }\end{array}$} \\
\hline & Range & $1.5-2.5$ & $1.6-2.2$ & \\
\hline
\end{tabular}

NS: no statistically significant difference

a: Mann Whitney test

This table showed that both studied groups had no significant differences regarding baseline values of mean ovarian volume and progesterone.

Table 3: Hormonal characteristics of patients following treatment in both groups

\begin{tabular}{|c|c|c|c|c|}
\hline & & $\begin{array}{l}\text { Group A } \\
\mathbf{N}=\mathbf{3 0}\end{array}$ & $\begin{array}{l}\text { Group B } \\
\mathbf{N}=\mathbf{3 0}\end{array}$ & p-value \\
\hline \multirow{2}{*}{$\begin{array}{l}\text { Ovarian volume } \\
(\mathbf{m m})\end{array}$} & Mean \pm SD & $7.15 \pm 2.21$ & $9.0 \pm 2.38$ & \multirow{2}{*}{$\begin{array}{l}0.002^{\mathrm{a}} \\
*\end{array}$} \\
\hline & Range & $4.4-11$ & $5.5-13$ & \\
\hline \multirow{2}{*}{$\begin{array}{l}\text { Progesterone } \\
\text { pg/ml }\end{array}$} & Mean \pm SD & $13.92 \pm 3.03$ & $11.46 \pm 3.92$ & \multirow{2}{*}{$\begin{array}{l}0.052^{\mathrm{a}} \\
\mathrm{NS}\end{array}$} \\
\hline & Range & $7-22$ & $6-18.5$ & \\
\hline
\end{tabular}

NS: no statistically significant difference

*: statistically significant difference

a: Mann Whitney test 
This table showed that following up patients after 3 months of treatment, no significant difference between both groups was existed regarding mean progesterone level however a significant lower ovarian volume was produced in patients of group A compared to group B.

Table 4: Hormonal characteristics of patients pre and post treatment in both groups

\begin{tabular}{|c|c|c|c|}
\hline & & $\begin{array}{l}\text { Group A } \\
\mathbf{N}=\mathbf{3 0}\end{array}$ & $\begin{array}{l}\text { Group B } \\
\mathbf{N}=\mathbf{3 0}\end{array}$ \\
\hline \multirow{2}{*}{$\begin{array}{l}\text { Ovarian volume } \\
(\mathbf{m m})\end{array}$} & Mean \pm SD Pre & $10.50 \pm 2.1$ & $10.38 \pm 1.91$ \\
\hline & Mean \pm SD Post & $7.15 \pm 2.21$ & $9.0 \pm 2.38$ \\
\hline \multicolumn{2}{|l|}{ Mean difference } & $3.34 \pm 2.27$ & $1.38 \pm 1.79$ \\
\hline \multicolumn{2}{|l|}{ p-value } & $0.000 * \Theta$ & $0.000 * \Theta$ \\
\hline \multirow{2}{*}{$\begin{array}{l}\text { Progesterone } \\
\mathrm{pg} / \mathrm{ml}\end{array}$} & Mean \pm SD Pre & $1.94 \pm 0.30$ & $1.89 \pm 0.13$ \\
\hline & Mean \pm SD Post & $13.92 \pm 5.03$ & $11.46 \pm 3.92$ \\
\hline \multicolumn{2}{|l|}{ Mean difference } & $11.98 \pm 3.96$ & $9.53 \pm 3.89$ \\
\hline \multicolumn{2}{|l|}{ p-value } & $0.001 * \theta$ & $0.001 * \Theta$ \\
\hline
\end{tabular}

(NS): no statistically significant difference

$\Theta$ : paired t test

This table showed that comparing ovarian volume pre and post therapy revealed significant decline when following up patients after months, added to that mean decline in group A was higher compared to group B. regarding improvement in serum progesterone in both studied groups, it was revealed highly significant increase in its level.

Table 5: Distribution of postoperative complications in both groups

\begin{tabular}{|l|l|l|l|l|l|}
\hline & \multicolumn{2}{l|}{$\begin{array}{l}\text { Group A } \\
\text { N=30 }\end{array}$} & \multicolumn{2}{l|}{$\begin{array}{l}\text { Group B } \\
\text { N=30 }\end{array}$} & p-value \\
\hline Ovulation rate & 21 & $70 \%$ & 13 & $43.3 \%$ & $0.034 \chi^{*}$ \\
\hline Regular cycles & 22 & $73.3 \%$ & 17 & $56.7 \%$ & $0.272 \chi$ NS \\
\hline Pregnancy rate & 17 & $56.7 \%$ & 7 & $23.3 \%$ & $\begin{array}{l}0.017 \chi \\
*\end{array}$ \\
\hline Abortion rate & 6 & $35.2 \%$ & 3 & $42.8 \%$ & $0.472 \chi$ NS \\
\hline
\end{tabular}

NS: no statistically significant difference

*: statistically significant difference

$\chi$ : Chi square test

This table showed that group A demonstrated significant ovulation and pregnancy rates compared to group B, in which 17 cases got pregnant and 6 of them have been aborted in a percent of $35.2 \%$ and in group B 7cases got pregnant 3 of them have been aborted in a percent of $42.8 \%$, while no significant differences were revealed between both groups regarding regular cycles or abortion rate.

Table 6: Comparison between pregnant and non-pregnant regarding different characteristics among group $\mathrm{A}$

\begin{tabular}{|c|c|c|c|c|}
\hline & & $\begin{array}{l}\text { Pregnancy } \\
\mathrm{N}=17\end{array}$ & $\begin{array}{l}\text { No pregnancy } \\
\mathrm{N}=13\end{array}$ & p-value \\
\hline Age & Mean \pm SD & $29.7 \pm 4.3$ & $30.0 \pm 3.6$ & $\begin{array}{l}0.902^{a} \\
\text { NS }\end{array}$ \\
\hline BMI & Mean \pm SD & $27.1 \pm 1.8$ & $28.4 \pm 1.2$ & $0.072^{\mathrm{a}} \mathrm{NS}$ \\
\hline \multirow[t]{2}{*}{ Type of infertility } & Primary & $10(58.8 \%)$ & $10(76.9 \%)$ & \multirow{2}{*}{$0.440 \chi \mathrm{NS}$} \\
\hline & Secondary & $17(41.2 \%)$ & $3(23.1 \%)$ & \\
\hline Duration of infertility & Mean \pm SD & 28.6 (month) \pm 7.1 & 28.4 (month) \pm 8.24 & $0.934^{\mathrm{a}} \mathrm{NS}$ \\
\hline Baseline ovarian volume & Mean \pm SD & $9.6 \pm 1.3$ & $11.6 \pm 2.3$ & $0.017 * \mathrm{a}$ \\
\hline Post ovarian volume & Mean \pm SD & $7.2 \pm 2.2$ & $6.99 \pm 2.2$ & $0.773 \mathrm{NS}^{\mathrm{a}}$ \\
\hline Baseline progesterone level & Mean \pm SD & $1.90 \pm 0.30$ & $1.99 \pm 0.32$ & $0.432^{a} \mathrm{NS}$ \\
\hline Post progesterone level & Mean \pm SD & $14.5 \pm 3.30$ & $13.1 \pm 3.6$ & $0.711^{\mathrm{a}} \mathrm{NS}$ \\
\hline \multirow[t]{2}{*}{ Menstrual pattern } & Regular & $4(23.5 \%)$ & $4(30.8 \%)$ & \multirow{2}{*}{$0.698 \chi \mathrm{NS}$} \\
\hline & Oligomenorrhea & $13(76.5 \%)$ & $9(69.2 \%)$ & \\
\hline \multicolumn{2}{|l|}{ Regular cycles } & $16(94.1 \%)$ & $5(46.2 \%)$ & $0.009 \chi^{*}$ \\
\hline \multicolumn{2}{|l|}{ Ovulation rate } & $16(94.1 \%)$ & $5(38.5 \%)$ & $0.002 \chi^{*}$ \\
\hline
\end{tabular}

NS: no statistically significant difference *: statistically significant difference

a: Mann Whitney test $\chi$ : Chi square test

This table showed that no significant difference revealed patients who got pregnant or not regarding age, BMI, duration of infertility, pre and post progesterone and their menstrual pattern before treatment, However, pregnant women had significant lower baseline ovarian volume compared to nonpregnant, also regular cycles were more prevalent among patients who got pregnant compared to who 
don't. Additionally ovulation rate was significantly higher among pregnant women compared to nonpregnant women.

Table 7: Comparison between pregnant and non-pregnant regarding different characteristics among group B

\begin{tabular}{|c|c|c|c|c|}
\hline & & $\begin{array}{l}\text { Pregnancy } \\
N=7\end{array}$ & $\begin{array}{l}\text { No pregnancy } \\
\mathrm{N}=\mathbf{2 3}\end{array}$ & p-value \\
\hline Age & Mean \pm SD & $32.2 \pm 3.9$ & $30.4 \pm 2.9$ & $\begin{array}{l}0.335^{\mathrm{a}} \\
\mathrm{NS}\end{array}$ \\
\hline BMI & Mean \pm SD & $27.4 \pm 1.9$ & $27.8 \pm 1.4$ & $0.532^{\mathrm{a}} \mathrm{NS}$ \\
\hline \multirow[t]{2}{*}{ Type of infertility } & Primary & $4(57.1 \%)$ & $14(60.9 \%)$ & \multirow{2}{*}{$\begin{array}{l}0.597 \chi \\
\text { NS }\end{array}$} \\
\hline & Secondary & $3(42.9 \%)$ & $9(39.1 \%)$ & \\
\hline $\begin{array}{ll}\text { Duration } \\
\text { infertility }\end{array}$ & Mean \pm SD & $\begin{array}{l}29.0 \text { (month) } \\
\pm 8.0\end{array}$ & $\begin{array}{l}29.8 \text { (month) } \\
\pm 6.9\end{array}$ & $0.631^{\mathrm{a}} \mathrm{NS}$ \\
\hline $\begin{array}{l}\text { Baseline ovarian } \\
\text { volume }\end{array}$ & Mean \pm SD & $9.2 \pm 0.95$ & $10.7 \pm 2.1$ & $0.118 \mathrm{NS}^{\mathrm{a}}$ \\
\hline $\begin{array}{ll}\text { Post } & \text { ovarian } \\
\text { volume } & \\
\end{array}$ & Mean \pm SD & $8.7 \pm 2.21$ & $9.1 \pm 2.4$ & $0.811 \mathrm{NS}^{\mathrm{a}}$ \\
\hline $\begin{array}{l}\text { Baseline } \\
\text { progesterone level }\end{array}$ & Mean \pm SD & $1.8 \pm 0.19$ & $1.9 \pm 0.18$ & $0.096^{\mathrm{a}} \mathrm{NS}$ \\
\hline $\begin{array}{l}\text { Post progesterone } \\
\text { level }\end{array}$ & Mean \pm SD & $11.1 \pm 4.5$ & $11.5 \pm 3.8$ & $0.737^{\mathrm{a}} \mathrm{NS}$ \\
\hline \multirow[t]{2}{*}{ Menstrual pattern } & Regular & $5(71.4 \%)$ & $5(21.7 \%)$ & \multirow{2}{*}{$0.026 \chi^{*}$} \\
\hline & Oligomenorrhea & $2(28.6 \%)$ & $18(78.3 \%)$ & \\
\hline \multicolumn{2}{|l|}{ Regular cycles } & $7(100 \%)$ & $10(43.5 \%)$ & $0.009 \chi^{*}$ \\
\hline \multicolumn{2}{|l|}{ Ovulation rate } & $6(85.7 \%)$ & $7(30.4 \%)$ & $0.025 \chi^{*}$ \\
\hline
\end{tabular}

NS: no statistically significant difference *: statistically significant difference

a: Mann Whitney test $\chi$ : Chi square test

This table showed that no significant difference revealed patients who got pregnant or not regarding age, BMI, duration of infertility, pre and post progesterone, and pre and post ovulation volume. Patients who became pregnant showed more regular cycles before and after treatment. Added to that, 6 women from those became pregnant showed ovulation compared to 7 out of 23 who didn't get pregnant.

Table 8: Correlation between progesterone level after 3 months of treatment and other different parameters in both groups

\begin{tabular}{|l|l|l|}
\hline \multirow{2}{*}{ Age } & $\begin{array}{l}\text { Group A } \\
\text { Progesterone level }\end{array}$ \\
\cline { 2 - 3 } & $\mathbf{R}$ & Sig \\
\hline BMI & 0.284 & $0.128 \mathrm{NS}$ \\
\hline Duration of infertility & 0.178 & $0.345 \mathrm{NS}$ \\
\hline Baseline ovarian volume & -0.261 & $0.164 \mathrm{NS}$ \\
\hline Post treatment ovarian volume & -0.205 & $0.277 \mathrm{NS}$ \\
\hline & -0.225 & $0.232 \mathrm{NS}$ \\
\hline & Group B \\
\hline Age & Progesterone level \\
\hline BMI & $\mathbf{R}$ & Sig \\
\hline Duration of infertility & 0.206 & $0.054 \mathrm{NS}$ \\
\hline Baseline ovarian volume & 0.022 & $0.906 \mathrm{NS}$ \\
\hline Post treatment ovarian volume & -0.279 & $0.135 \mathrm{NS}$ \\
\hline
\end{tabular}

NS: statistically significant difference

This table showed no significant correlation between serum progesterone level after therapy and different parameters in both study groups.

Table 9: Comparison between group I and group II as regards to Laparoscopic complications after treatment

\begin{tabular}{|l|l|l|l|}
\hline Time & $\begin{array}{l}\text { Group I } \\
(\mathbf{N}=30)\end{array}$ & $\begin{array}{l}\text { Group II } \\
(\mathbf{N}=30)\end{array}$ & \#P \\
\hline Present & $1.0(3.3 \%)$ & $1.0(3.3 \%)$ & \multirow{2}{*}{1.000} \\
\hline Absent & $29(36.7 \%)$ & $29(36.7 \%)$ & \\
\hline
\end{tabular}


This table showed that frequency of laparoscopic complications after drilling was non-significantly different in both groups after drilling.

\section{Discussion}

In the present study, 60 patients with PCO were resistant to clomiphene citrate therapy had undergone ovarian drilling. Those patients had been classified into 2 groups according to the selected therapy. Two trails had been compared; group A had received metformin (850 mg twice daily) plus dexamethasone ( $2 \mathrm{mg}$ daily from day 5 to day 14 monthly) for 3 months while group B had received metformin only ( $850 \mathrm{mg}$ twice daily).Our study showed that both studied groups had no significant differences regarding baseline values of mean ovarian volume and progesterone and after following up patients after 3 months of treatment, no significant difference between both groups was existed regarding mean progesterone level however a significant lower ovarian volume was produced in patients of group A compared to group B.Also this study showed that comparing ovarian volume pre and post therapy revealed significant decline when following up patients after months, added to that mean decline in group A was higher compared to group B. regarding improvement in serum progesterone in both studied groups, it was revealed highly significant increase in its level.Our study also showed that group A demonstrated significant ovulation and pregnancy rates compared to group B, while no significant differences were revealed between both groups regarding regular cycles or abortion rate, no significant difference revealed patients who got pregnant or not regarding age, BMI, duration of infertility, pre and post progesterone and their menstrual pattern before treatment, However, pregnant women had significant lower baseline ovarian volume compared to nonpregnant, also regular cycles were more prevalent among patients who got pregnant compared to who don't. Additionally ovulation rate was significantly higher among pregnant women compared to non-pregnant women.There was no significant difference revealed patients who got pregnant or not regarding age, BMI, duration of infertility, pre and post progesterone and pre and post ovulation volume. Patients who became pregnant showed more regular cycles before and after treatment. Added to that, 6 women from those became pregnant showed ovulation compared to 7 out of 23 who didn't have pregnant.

Finally, our study showed no significant correlation between serum progesterone level after therapy and different parameters in both study groups. Results of Elnashar et al. ${ }^{(9)}$ and Parsanezhad et al. ${ }^{(10)}$ agreed with the findings of our study and they showed that , in clomiphene-resistant women, dexamethasone plus clomiphene increases ovulation and the pregnancy rate, compared with clomiphene alone. Wahab et al. (11) studied thirty-five female patients, all with a diagnosis of PCOS and abnormal laboratory blood levels were given $850 \mathrm{mg}$ of metformin twice a day for six months, the results of this study was agreed with the findings of our study in improvement in all laboratory values after, it also showed that metformin helped with weight reduction with an average weight loss of $4.7 \mathrm{~kg}$., but did not show any improvement in clinical hyperandrogenism. Our results agreed with those of Hashim et al. (12) that explored in detail the effects of combining the use of these two pharmaceutical agents, the purpose of this review was to compare the effects of metformin and clomid combined therapy to those of other methods of ovulation induction in clomid-resistant PCOS, including gonadotrophins, laparoscopic ovarian drilling, letrozole (a third-generation aromatase inhibitor), dexamethasone and natural insulin sensitizers. Primary clinical outcomes of this study included the rate of ovulation (confirmed by serum progesterone on cycle days 21-23, reports of regular menses, or transvaginal ultrasound), and clinical pregnancy rate as defined by the presence of a gestational sac and fetal heartbeat on 7 week ultrasound scan.Our results agreed with those of Elgafor et al. ${ }^{(\mathbf{1 3})}$ which explored that not only metformin, but also letrozole and bilateral ovarian drilling, are similarly effective as second-line treatment for women with PCOS who were not able to conceive with clomid alone.

\section{Conclusion}

In this study, we compared the effect of Metformin and Dexamethasone administration after LOD in patient with CC resistant PCO with the effect of Metformin after Laparoscopic ovarian drilling, the results showed that group 
A demonstrated significant ovulation and pregnancy rates compared to group $\mathrm{B}$. We concluded that there was a good value of administration of Dexamethasone with Metformin after Laparoscopic ovarian drilling in patients with clomiphene resistant polycystic ovarian disease especially those patients with normal DHEAS levels.

\section{Recommendations}

In our study, adding Dexamethasone in early follicular phase with Metformin in patients with normal DAHEAS level had showed a better effect on ovulation especially in patients with higher body mass index than in those who administrated Metformin alone after Laparoscopic ovarian drilling, so we recommend further studies to compare the effect of Metformin and Dexamethasone in patients with low body mass index and normal or abnormal DAHEAS level.

\section{References}

1. Azziz R, Woods KS and Reyna R (2004): The prevalence and features of the polycystic ovary syndrome in an unselected population. J. Clin. Endocrinol. Metab., 89:2745-2753.

2. Twig G, Yaniv $G$ and Levine $H$ (2016): Body-Mass index in 2.3 million adolescents and cardiovascular death in adulthood. N. Engl. J. Med., 374:24302439.

3. Rosenfield RL, Mortensen M, Wroblewski $\mathrm{K}$ et al. (2011): Determination of the source of androgen excess in functionally atypical polycystic ovary syndrome by a short dexamethasone androgen-suppression test and a low-dose ACTH test. Hum Reprod., 26:3138.

4. Kumar A, Woods KS, Bartolucci AA et al. (2005): Prevalence of adrenal androgen excess in patients with the polycystic ovary syndrome (PCOS). Clin. Endocrinol., 62:644-652.

5. Legro RS, Arslanian SA and Ehrmann DA (2013): Diagnosis and treatment of polycystic ovary syndrome: an Endocrine Society clinical practice guideline. J. Clin. Endocrinol. Metab., 98:4565-4572.

6. Tang T, Lord JM and Norman RJ (2012): Insulin-sensitising drugs (metformin, rosiglitazone, pioglitazone, Dchiro-inositol) for women with polycystic ovary syndrome, oligo amenorrhea and sub- fertility. Cochrane Database Syst.
Rev., $\quad$ CD003053.httpsllwww. Cochranelibrary.com.doi $\backslash 10.1002 \backslash 146518$ 58.C

7. Vanky E, Salvesen KA and Carlsen SM (2004): Six-month treatment with low-dose dexamethasone further reduces androgen levels in PCOS women treated with diet and lifestyle advice and metformin. Human Reprod., 19(3):529-533.

8. Filicori M, Butler JP and Crowley WF (1984): Neuroendocrine regulation of corpus luteum in the human: evidence for pulsatile progesterone secretion. J. Clin. Invest., 73:1638-1647.

9. Elnashar A, Abdelmageed E, Fayed M and Sharaf M (2006): Clomiphene citrate and dexamethasone in treatment of clomiphene citrate-resistant polycystic ovary syndrome: a prospective placebo controlled study. Hum. Reprod.,21(7):1805- 1808

10. Parsanezhad ME, Alborzi S, Motazedian $S$ and Omrani G (2002): Use of dexamethasone and clomiphene citrate in the treatment of clomiphene citrate resistant patients with polycystic ovary syndrome and normal dehydroepiandrosterone sulfate levels: placebo-controlled trial. Fertil .Steril., 78 (5):1001-1004.

11. Wahab S, Zahoor F and Karim R (2013): Role of metformin in polycystic ovarian syndrome. Journal of Postgraduate Medical Institute, 27(2):179-183.

12. Abu Hashim H, Foda $O$ and Ghayaty $E$ (2015): Combined metformin clomiphene in clomiphene-resistant polycystic ovary syndrome: a systematic review and metaanalysis of randomized controlled trials. Acta Obstet. Gynecol. Scand., 94(9): 921930.

13. Elgafor A (2013): Efficacy of combined metformin-letrozole in comparison with bilateral ovarian drilling in clomipheneresistant infertile women with polycystic ovarian syndrome. Arch Gynecol. Obstet., 288(1): 119-123. 